however, the exchange of people between Norwegian universities and industry seems to be every bit as good as would be expected in Western Europe. The NTNF has had some success in tempting postdoctoral fellows from abroad to work in Norway-it awarded postdoctoral fellowships to twenty-two people during 1968, and past, experience shows that something like 15 per cent of these will stay on for longer than the term of years first contracted for. By contrast, however, it is rather puzzling that there has recently been a decline in the enrolment of students at Norwegian universities-in 1967 a total of 5,350 Norwegian students embarked on higher education, which represents a considerable decrease in the numbers of new students for the departments of philosophy and science, but in Norway, as elsewhere, the social sciences are booming.

\title{
IRELAND
}

\section{Much Room for Growth}

THE past year has been the first in which the Irish Republic has been provided with a coordinating body for scientific research and development. The National Science Council was in fact established after an examination carried out jointly by the Irish Republic and the OECD in 1963 and it came into being in January 1968. Understandably, there has been very little time so far for the council to have made its mark under the several independent agencies which at present support research in Ireland. It is, however, plain that the council has come into being at a time when expenditure on scientific research is growing quickly. It is estimated that total expenditure, from all sources, on research and development amounted to $£ 3.8$ million in 1963 and that this had increased to $£ 6 \cdot 1$ million in 1967. Although this represents a 9 per cent increase each year, expenditure on research and development is still a comparatively small proportion-roughly 0.6 per cent-of the GNP. Evidently one of the council's first preoccupations will be to devise means of increasing the growth of expenditure.

The council has, however, laid down that it will do its best to encourage the development of industrial projects and for this reason has devised a scheme for providing research and development grants to industry, ostensibly with the intention of reducing the dependence of Eire on "imported know-how". The scheme is to provide for up to 50 per cent of the cost of research programmes over a period of 3 years so long as the work concerned is carried out in Ireland. This scheme, unusual among government devices for stimulating research and development in industry, will-if approved-be a means by which industry can take the initiative in guiding the direction of industrial research. This is consistent with the marching orders provided for the council early in 1968 by $\mathrm{Mr}$ C. J. Haughey, who emphasized that anything the council recommended as a national science policy should be concerned with "those aspects of science which foster economic progress".

In academic research, the council acknowledges that there is a need for more research and better coordination. What the council would like to see is a scheme whereby it could make grants for the support of research projects, but it seems in this connexion to be seeking to foster close links with industry even at a time when there is good reason to suspect that the universities may not be sufficiently well endowed to serve the council's aim of attracting emigrant Irishmen back to Ireland.

The future of university research in Ireland will be influenced, for better or for worse, by the decision at the end of 1967 that the University of Dublin (Trinity College,
Dublin) should be merged with the National University of Ireland (University College, Dublin). The plan is that the merger should be complete within 2 years from now. All the signs are that the merger is proving to be difficult. Much will depend on the extent to which the religious differences between the two foundations can be forgotten and on the extent to which the National Science Council ean sweeten the pill by providing extra money.

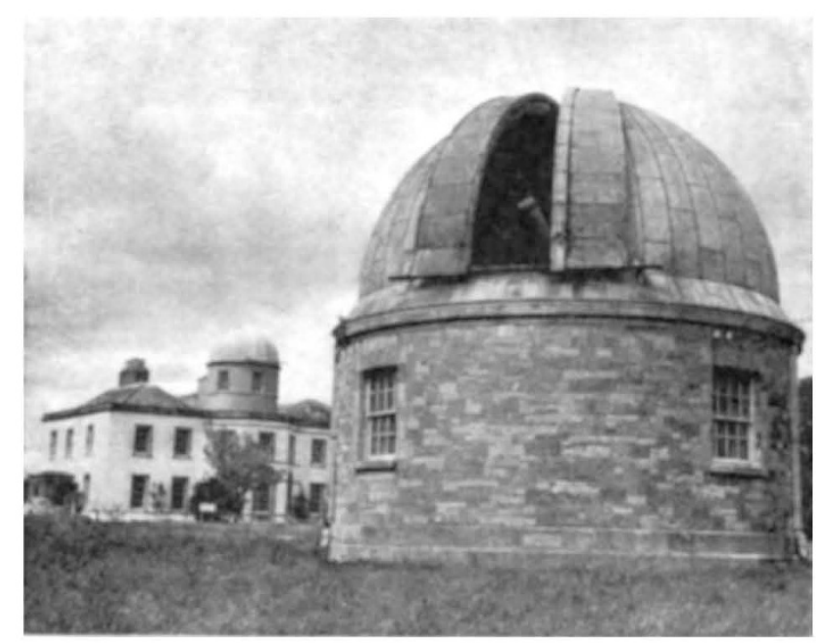

Dunsink Observatory, Dublin.

There have been a number of developments in the organization of research institutes maintained by the Irish Government. It is, for example, intended to reorganize the Geological Survey Office, chiefly with the intention of converting this into a device for playing a fuller part in the economic development of Ireland, chiefly by intensifying the effort spent on prospecting. There is an ambitious plan to reorganize the National Standards Laboratory, the Institute for Industrial Research and Standards, chiefly again by providing closer links with industry. The National Science Council is asking that the laboratory's budget should be increased substantially from the $£ 500,000$ spent in 1968-69. The detailed proposals which the council makes would suggest that the laboratory would grow into a replica, possibly on a small scale and certainly with its own national character, of the National Physical Laboratory in Britain or the National Standards Laboratory in the United States. 